CLINICAL STUDY

\title{
Maternal plasma corticotrophin-releasing factor and urocortin levels in post-term pregnancies
}

Michela Torricelli, Erika Ignacchiti, Alessia Giovannelli, Angelica Merola, Elisa Scarpetti, Giulia Calonaci, Enrico Picciolini, Pasquale Florio, Fernando M Reis, Elizabeth A Linton ${ }^{1}$ and Felice Petraglia

Chair of Obstetrics and Gynaecology, Department of Paediatrics, Obstetrics and Reproductive Medicine, University of Siena, Policlinico 'Le Scotte', viale Bracci 53100 Siena, Italy ${ }^{1}$ Nuffield Department of Obstetrics and Gynaecology, John Radcliffe Hospital, University of Oxford,Oxford, UK

(Correspondence should be addressed to F Petraglia: Email: petraglia@unisi.it)

\begin{abstract}
Objective: Corticotrophin-releasing factor (CRF) and urocortin are two placental neuropeptides that are involved in the mechanisms of labour by modulating myometrial activity. Maternal plasma levels of both CRF and urocortin are increased at term and preterm labour, whilst those of CRF are reduced in women who are destined to experience post-term delivery. The present study evaluated maternal plasma levels in term and post-term pregnancies out of labour.

Design: A group of healthy pregnant women was enrolled and subdivided as follows: (i) at term out of labour ( $n=19 ; 276 \pm 0.7$ days of gestation; samples collected at the time of elective caesarean section due to previous uterine surgery); (ii) post-term $(n=19 ; 291 \pm 1.4$ days of gestation), from whom samples were collected before induction of labour.

Methods: Urocortin and CRF measurements by radioimmunoassay; digital palpatory cervical examination and Bishop score computation; cervical length and funnelling presence assessment by transvaginal ultrasonography.

Results: Maternal plasma CRF concentrations were significantly $(P<0.05)$ lower whilst those of urocortin were unchanged in post-term compared with term pregnancy. However, CRF and urocortin levels were both significantly $(P<0.05$ and $P<0.001$ respectively) higher in pregnancies delivered within $12 \mathrm{~h}$ of labour induction than in those that remained undelivered, and were significantly correlated with the induction-delivery interval (CRF: $r=-0.676, P=0.0015$; urocortin: $r=-0.783$, $P<0.0001$ ).

Conclusions: CRF and urocortin levels are decreased and unchanged, respectively, in post-term pregnancy when compared with term pregnancy. Both CRF and urocortin correlate with the time of labour onset after induction. Since CRF derives from the placenta, and urocortin from the fetus, the concerted expression of these neuropeptides appears to be relevant in determining the length of human gestation.
\end{abstract}

European Journal of Endocrinology 154 281-285

\section{Introduction}

Prolonged gestation is largely an enigma but may be due to a defect in the hormonal milieu that leads to the onset of labour $(1,2)$. Indeed, the duration of pregnancy is determined by a shift in the equilibrium between inhibitors and activators of myometrial contractility, so that parturition results from a complex interplay between several placental players able to influence molecular pathways driving the onset of labour (2). Corticotrophin-releasing factor (CRF) and urocortin are local peptides that may be part of the hormonal milieu controlling uterine contractility (3).

CRF is a 41-amino acid neuropeptide expressed by gestational tissues throughout pregnancy and secreted into the maternal circulation $(2,3)$. Urocortin is a 40amino acid neuropeptide, sharing $45 \%$ sequence identity to CRF (4), which is also expressed by the human placenta, decidua and foetal membranes (5). Binding to diverse receptor subtypes expressed by the human placenta and foetal membranes (6), CRF and urocortin stimulate the local release of uterotonins, i.e. adrenocorticotrophin (ACTH), oxytocin and prostaglandins (7-10). Furthermore, the binding of CRF and urocortin to their myometrial receptors triggers different pathways that result in myometrial quiescence when activated by CRF, and myometrial contractility when stimulated by urocortin (11). Finally, both CRF (12) and urocortin (13) levels are increased in the maternal circulation at term and preterm labour. Although it is 
possible that their increased levels at labour may be a consequence rather than a cause of human parturition, the in vitro evidence for a role of CRF in myometrial activity (11), together with the finding of reduced levels of plasma CRF in women who are destined to experience post-term delivery (14), suggest that CRF may act directly as a trigger for parturition in humans.

Since no data are as yet available on urocortin, in the present study we measured its maternal plasma levels in term and post-term pregnancies out of labour.

\section{Materials and methods}

A group of healthy pregnant women $(n=38)$ was enrolled in our Division of Obstetrics and Gynaecology, and subdivided as follows: (i) at term out of labour $(n=19 ; 276 \pm 0.7$ days of gestation; samples collected at the time of elective caesarean section due to previous uterine surgery); (ii) post-term $(n=19 ; 291 \pm 1.4$ days of gestation; samples collected before induction of labour).

Written informed consent was obtained from each pregnant woman and the permission of the Local Human Investigation Committee was granted for the study. The exclusion criteria were multiple pregnancies, diabetes, hypertension, foetal anomaly, maternal or foetal infection, foetal growth restriction, cardiotocographic evidence of foetal distress and an Apgar score at $1 \mathrm{~min}$ of $<7$. All pregnancies were dated by ultrasound, with measurement of the biparietal diameter, head circumference, femur length, and abdominal circumference; their clinical characteristics are summarized in Table 1.

In all post-term pregnancies, a digital palpatory cervical examination was performed, the Bishop score was assigned (15), and all five parameters of the Bishop scoring system (dilatation, effacement, station, cervical consistency, and cervical position) were recorded separately. After the digital examination and before starting labour induction, patients were submitted to transvaginal ultrasonography with the use of Siemens Sonoline ELEGRA real-time ultrasound scan equipment (Erlangen, Germany) with a $4.5-7.0 \mathrm{MHz}$ transvaginal probe, to measure the cervical length and to assess the presence of funnelling. Funnelling was defined as a V- or Yshape triangle with a protrusion of the amniotic

Table 1 Summary of clinical data.

\begin{tabular}{lcc}
\hline & $\begin{array}{c}\text { At term not in } \\
\text { labour }\end{array}$ & $\begin{array}{c}\text { Post-term not } \\
\text { in labour }\end{array}$ \\
\hline Number of subjects & 19 & 19 \\
Parity & $1.05 \pm 0.3$ & $1.2 \pm 0.5$ \\
Maternal age (years) & $28.7 \pm 1.2$ & $28.6 \pm 2.0$ \\
Gestation days at delivery & $276 \pm 0.7$ & $291 \pm 1.4$ \\
Birth weight (g) & $3344 \pm 66$ & $3360 \pm 56$ \\
\hline
\end{tabular}

membranes $3 \mathrm{~mm}$ or more into the internal cervical os as measured along the lateral border of the funnel (16). Labour was induced by administering an intravaginal prostaglandin pessary (dinoprostone; propess $10 \mathrm{mg}$; Ferring AB, Limhamn, Sweden), that was removed after the $12-\mathrm{h}$ observation period if there were no cervical changes or in any of the following events: initiation of labour, spontaneous rupture of membranes, amniorhexis, uterine hyperstimulation or hypertonus, foetal distress, or secondary systemic effects such as nausea, fever, vomiting, diarrhoea, tachycardia or hypertension. If an increase in the Bishop score of 3 or more points above the baseline was achieved, the pessary was removed, amniotomy was performed if possible and oxytocin was started as necessary. Oxytocin infusion was not begun until at least 30 min after removal of the pessary. Our protocol included intravenous oxytocin as recommended by the American College of Obstetricians and Gynecologists (17) and was to be continued for a maximum of $8 \mathrm{~h}$ unless contraindications arose (17). Amniotomy was performed at the discretion of the attending physician. The onset of active labour was considered as $4 \mathrm{~cm}$ dilatation with regular contractions every 2-3 min.

Blood samples were drawn by using a polypropylene syringe and a butterfly needle and then transferred to chilled tubes containing ethylenediaminetetra-acetic acid $(10 \mathrm{mg} / \mathrm{ml}$ blood). The tubes were centrifuged immediately at $4{ }^{\circ} \mathrm{C}(3000 \mathrm{~g}$ for $10 \mathrm{~min})$. All plasma samples were kept at $-80^{\circ} \mathrm{C}$ until assay.

\section{Urocortin assay}

Maternal plasma levels were measured using previously published methodology (13), except for the delayed addition of tracer to improve assay sensitivity. Briefly, duplicate $100 \mu \mathrm{l}$ aliquots of plasma extract or human urocortin (1-40) standard were mixed with $100 \mu \mathrm{l}$ assay buffer containing rat urocortin (1-40) antiserum at 1:2100 dilution and incubated for $40 \mathrm{~h}$ at $4{ }^{\circ} \mathrm{C}$. Buffer $(100 \mu \mathrm{l})$ containing approximately 2000 c.p.m. iodine ${ }^{125}$-labelled human urocortin $(1-40)$ was then added and the tubes incubated for a further $6 \mathrm{~h}$ prior to the addition of pre-precipitated sheep anti-rabbit second antibody, as previously described (13). The specificity of the urocortin antiserum had been checked by measuring the cross-reactivity of peptides with sequence homology in the urocortin assay, i.e. human CRF $(1-20)$ and human CRF (1-41) (Peninsula Laboratories, St Helens, Merseyside, UK), human urocortin II (Stresscopinrelated peptide $\left.(6-43) \mathrm{NH}_{2}\right)$ and human urocortin III (Stresscopin (3-40) $\mathrm{NH}_{2}$ ) (Phoenix Pharmaceuticals Inc., Belmont CA, USA) as well as with ACTH, sauvagine and urotensin 1 (Sigma Chemicals Co, St Louis, MO, USA) and thyroglobulin; none of these molecules displayed significant cross-reactivity even at high concentration $(1 \mu \mathrm{g} / \mathrm{ml})$. Urocortin levels in the study 
samples were measured in a blinded fashion in a single assay; the assay had a sensitivity of approximately $50 \mathrm{pg} / \mathrm{ml}$ with intra-assay and interassay variations of $8 \%$ and $13 \%$ respectively.

\section{CRF assay}

CRF was measured with the CRF-specific immunoradiometric assay as described previously (18), using human CRF (Peninsula Laboratories) as standard. The assay had a sensitivity of approximately $40 \mathrm{pg} / \mathrm{ml}$ with intra-assay and interassay variations of $5 \%$ and $11 \%$ respectively.

\section{Statistical analysis}

After normality testing had confirmed that both CRF and urocortin levels were normally distributed, the data were expressed as means \pm standard error (s.E.), and analysed for statistically significant differences by unpaired $t$-test. When two groups were compared, the paired $t$-test was used to compute statistical significance. Correlation between CRF and urocortin levels with the induction delivery interval (in min) was calculated by using the Pearson's correlation test. Statistical significance was assumed whenever $P<0.05$.

\section{Results}

Table 2 shows the characteristics of post-term patients subjected to labour induction. The group of patients $(n=9)$ who achieved delivery within $12 \mathrm{~h}$ had the same parity, cervical length, Bishop score and presence of funnelling as the remaining patients $(n=10)$ who delivered after $12 \mathrm{~h}$ of prostaglandin exposure. Neither cervical length nor Bishop score were significantly correlated with plasma CRF or urocortin concentrations.

CRF and urocortin were measurable in all plasma samples evaluated. In detail, CRF concentrations were significantly $(P<0.05)$ lower $(1.36 \pm 0.3 \mathrm{ng} / \mathrm{ml})$ whilst maternal plasma urocortin levels were unchanged $(99.65 \pm 4.1 \mathrm{pg} / \mathrm{ml})$ in post-term compared

Table 2 Characteristics of the patients who succeeded or failed to deliver by the vaginal route within 12 hours of labour induction.

\begin{tabular}{lrrr}
\hline & \multicolumn{2}{c}{ Delivery within 12 h } & \\
& Yes $(n=9)$ & No $(n=10)$ & $\boldsymbol{P}$ value \\
\hline Age & $28.7 \pm 1.7$ & $29.3 \pm 1.9$ & NS \\
Parity & $1.2 \pm 0.5$ & $1.2 \pm 0.5$ & NS \\
Bishop score (total) & $3(2-5)$ & $3(2-5)$ & NS \\
Bishop score & $2(1-2)$ & $2(1-2)$ & NS \\
(dilatation + effacement) & & & \\
Cervical length (mm) & $22.7 \pm 1.0$ & $23.2 \pm 2.0$ & NS \\
Funnelling present & $4(47 \%)$ & $3(30 \%)$ & NS \\
\hline
\end{tabular}

NS, not significant. with term (CRF: $2.61 \pm 0.3 \mathrm{ng} / \mathrm{ml}$; urocortin: $91.1 \pm 1.8 \mathrm{pg} / \mathrm{ml}$ ) pregnancy (Fig. 1). However, maternal plasma CRF $(1.52 \pm 0.2 \mathrm{ng} / \mathrm{ml})$ and urocortin $(112.2 \pm 4.8 \mathrm{pg} / \mathrm{ml})$ levels were both significantly $(P<0.05$ and $P<0.001$ respectively) higher in postterm pregnancies delivered within $12 \mathrm{~h}$ of labour induction than in those that remained undelivered after $12 \mathrm{~h}$ of induced labour (CRF: $0.69 \pm 0.2 \mathrm{ng} / \mathrm{ml}$; urocortin: $88.33 \pm 3.7 \mathrm{pg} / \mathrm{ml}$ ) (Fig. 2), and were significantly correlated with the induction-delivery interval (CRF: $r=-0.676, \quad P<0.0015$; urocortin: $r=-0.783$, $P<0.0001)$ (Fig. 3).

\section{Discussion}

The onset of labour is timed by a complicated and not yet fully discovered mechanism, and is characterised by changes in many of the gestational tissues, which are prerequisites for the onset of labour. These include the completion of foetal organ maturation, ripening of the cervix and activation of the contractile apparatus of the myometrium (which is maintained in a quiescent state throughout pregnancy until this time) (2). In this regard, both CRF and urocortin have already been evaluated for their differing modulatory effects on uterine contractility. Whilst urocortin indirectly triggers a univocal myometrial response, i.e. activation of contractility $(10,11), \mathrm{CRF}$ on the other hand promotes
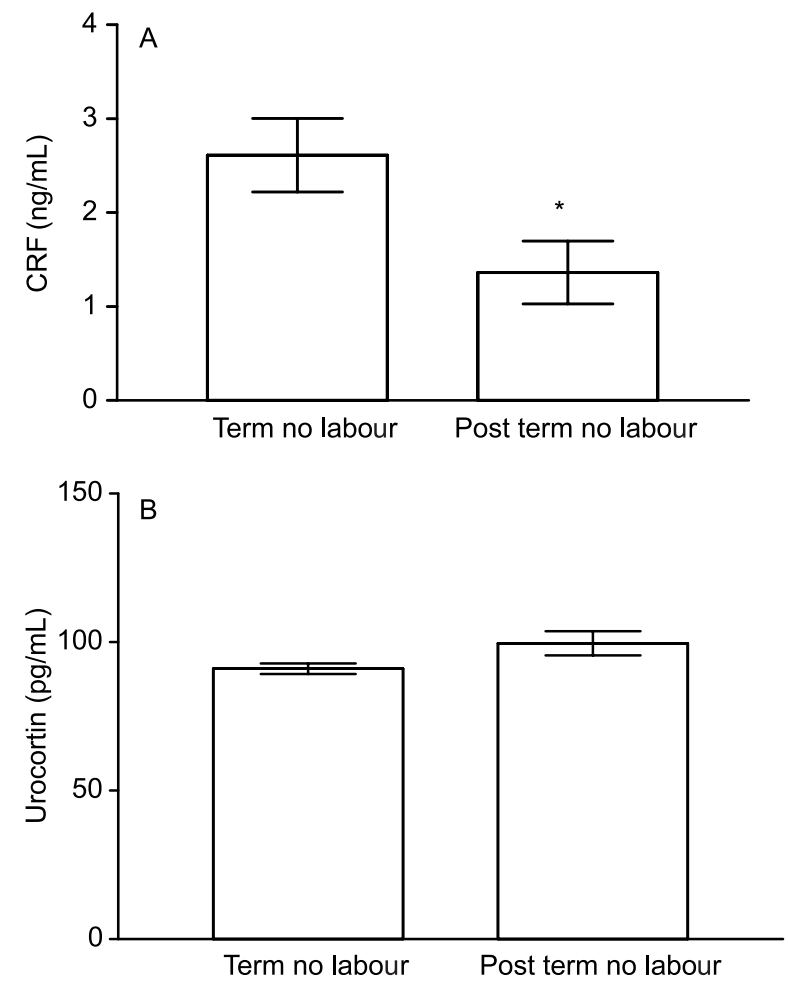

Figure 1 Maternal plasma CRF (A) and urocortin (B) levels in patients at term and post-term pregnancy. ${ }^{*} P<0.05$. 

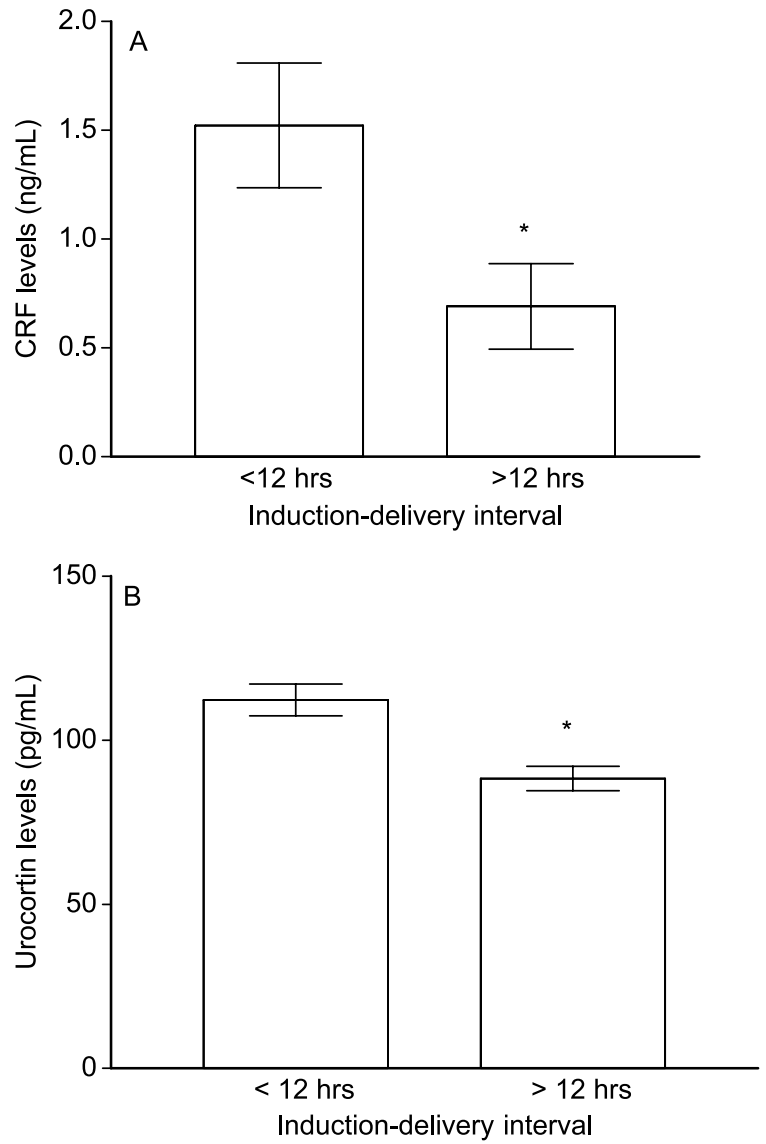

Figure 2 Maternal plasma CRF (A) and urocortin (B) levels and induction-delivery interval: levels were significantly higher in patients who proceeded to delivery within $12 \mathrm{~h}$ from induction. ${ }^{*} P<0.05$.

relaxation of the myometrium during most of pregnancy, but contraction in late pregnancy when the myometrial intracellular pathways have already been primed by uterotonic agents (11). Taken together, these data implicate CRF and urocortin as activators of multiple mechanisms that together contribute to the initiation of parturition and labour, and that also involve local events in the human placenta such as the induction of secretion of several uterotonins (3, $11,12)$.

In the present study we found that levels of CRF were lower, whilst those of urocortin were unchanged in post-term compared with term pregnancies out of labour, suggesting a possible delay in the hormonal changes associated with the onset of labour, since concentrations of both neurohormones have been reported as significantly increased at term and preterm labour $(2,3,12-14)$. This evidence suggests that in the presence of lower CRF secretion, the cascade of events that induces labour and signals the end of pregnancy is not activated, and therefore pregnancy will continue (14). Urocortin levels, however, were not reduced in post-term pregnancy; actually they were higher in the
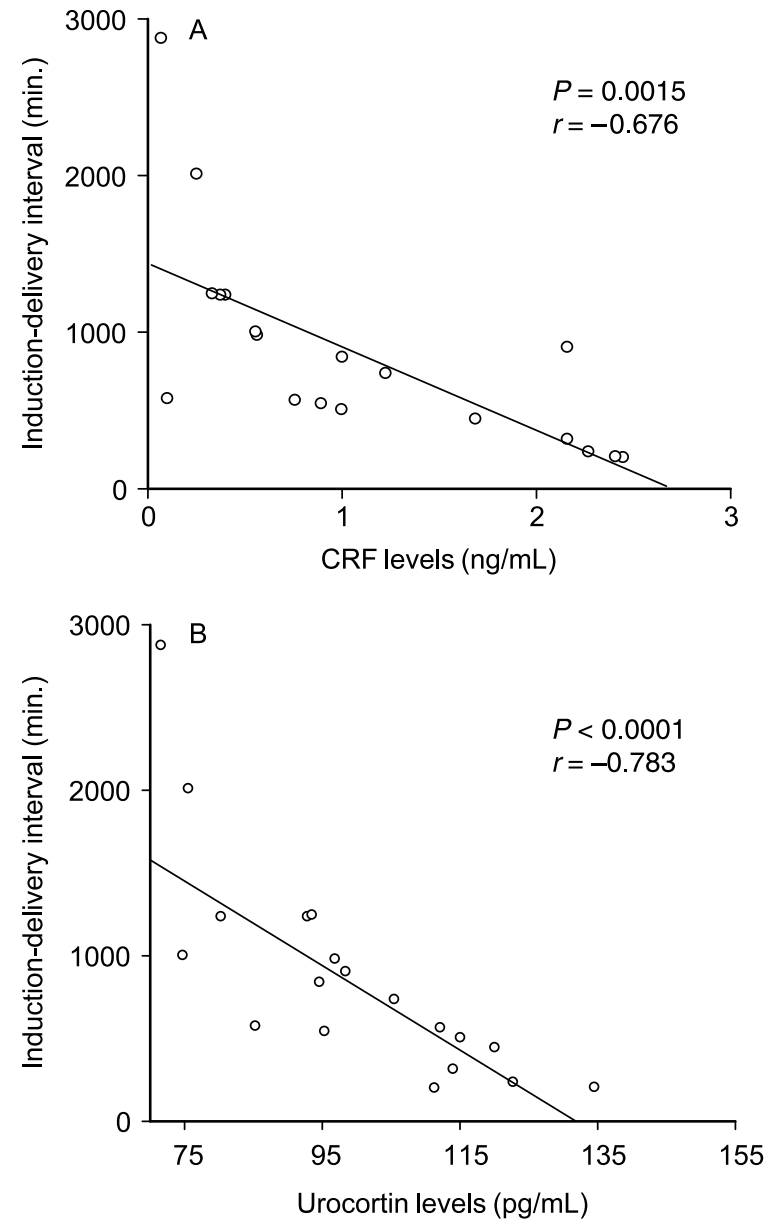

Figure 3 Maternal plasma CRF (A) and urocortin (B) levels were significantly and inversely correlated to the induction-delivery interval (min).

subset of patients that responded rapidly to induction than in term gestation controls. This observation suggests that urocortin may not be as important in labour initiation as it is in sensitisation to labour inducers. In fact, we have previously shown that urocortin does not initiate contraction but greatly amplifies the contractile response of myometrial strips stimulated in vitro with prostaglandin (10).

The second result of the present study, relating to the higher levels of CRF and urocortin in pregnancies delivered within $12 \mathrm{~h}$ of labour induction than in those that remained undelivered, would support the idea that the combined effects of both neuropeptides are of relevance in predisposing a myometrial response to labour inducers (i.e. prostaglandins).

Whatever the role of circulating CRF and urocortin in post-term pregnancy, their sources warrant discussion. Previous work has shown that foetal urocortin levels are higher (13), whilst those of CRF are considerably lower $(19,20)$ than those in the mother, suggesting a placental source for CRF, and a foetal origin for urocortin levels in maternal blood. Further underlining this 
difference is the evidence that placental CRF mRNA expression increases throughout gestation (21), whilst that of urocortin does not (22), and that maternal plasma CRF levels increase until term $(3,23)$, whilst urocortin concentrations are constant during gestation (24). Together, these findings led us to hypothesise the existence of a 'foetal' as well as a 'placental' clock (14) that, through the secretion of urocortin and CRF respectively, may determine the length of human gestation.

\section{References}

1 WHO, WHO recommended definitions, terminology and format for statistical tables related to the perinatal period and use of a new certificate for cause of perinatal deaths: modifications recommended by FIGO as amended October 14. Acta Obstetrica et Gynecologica Scandinavica 197756 247-253.

2 Challis JRG, Matthews SG, Gibb W \& Lye SJ. Endocrine and paracrine regulation of birth at term and preterm. Endocrine Reviews $200021514-550$.

3 Florio P, Vale W \& Petraglia F. Urocortins in human reproduction. Peptides $2004251751-1757$.

4 Donaldson CJ, Sutton SW, Perrin MH, Corrigan AZ, Lewis KA, Rivier JE, Vaughan JM \& Vale WW. Cloning and characterization of human urocortin. Endocrinology 1996137 2167-2170.

5 Petraglia F, Florio P, Gallo R, Simoncini T, Saviozzi M, Di Blasio AM, Vaughan J \& Vale W. Human placenta and fetal membranes express human urocortin mRNA and peptide. Journal of Clinical Endocrinology and Metabolism 199681 3807-3810.

6 Florio P, Franchini A, Reis FM, Pezzani I, Ottaviani E \& Petraglia F. Human placenta, chorion, amnion and decidua express different variants of corticotropin-releasing factor receptor messenger RNA. Placenta $20002132-37$.

7 Petraglia F, Sawchenko PE, Rivier J \& Vale W. Evidence for local stimulation of ACTH secretion by corticotropin-releasing factor in human placenta. Nature 1987328 717-719.

8 Florio P, Lombardo M, Gallo R, Di Carlo C, Sutton S, Genazzani AR \& Petraglia F. Activin A, corticotropin-releasing factor and prostaglandin F2 alpha increase immunoreactive oxytocin release from cultured human placental cells. Placenta 199617 307-311.

9 Jones SA \& Challis JR. Effects of corticotropin-releasing hormone and adrenocorticotropin on prostaglandin output by human placenta and fetal membranes. Gynecologic and Obstetric Investigation 199029 165-168.

10 Petraglia F, Florio P, Benedetto C, Marozio L, Di Blasio AM, Ticconi C, Piccione E, Luisi S, Genazzani AR \& Vale W. Urocortin stimulates placental adrenocorticotropin and prostaglandin release and myometrial contractility in vitro. Journal of Clinical Endocrinology and Metabolism 199984 1420-1423.
11 Hillhouse EW \& Grammatopoulos DK. Role of stress peptides during human pregnancy and labour. Reproduction $2002 \mathbf{1 2 4}$ 323-329.

12 McLean M \& Smith R. Corticotrophin-releasing hormone and human parturition. Reproduction 2001121 493-501.

13 Florio P, Torricelli M, Galleri L, De Falco G, Leucci E, Calonaci G, Picciolini E, Ambrosini G, Linton EA \& Petraglia F. High fetal urocortin levels at term and preterm labor. Journal of Clinical Endocrinology and Metabolism $2005905361-5365$.

14 McLean M, Bisits A, Davies J, Woods R, Lowry P \& Smith R. A placental clock controlling the length of human pregnancy. Nature Medicine 19951 460-463.

15 Bishop EH. Pelvic scoring for elective induction. Obstetrics and Gynecology 196424 266-268.

16 Boozarjomehri F, Timor-Tritsch I, Chao CR \& Fox HE. Transvaginal ultrasonographic evaluation of the cervix before labor: presence of cervical wedging is associated with shorter duration of induced labor. American Journal of Obstetrics and Gynecology $19941711081-1087$.

17 American College of Obstetricians and Gynecologists. Induction of labor. ACOG Technical Bulletin no. 217. Washington, DC: ACOG, 1995.

18 Florio P, Cobellis L, Woodman J, Severi FM, Linton EA \& Petraglia F. Levels of maternal plasma corticotropin-releasing factor and urocortin during labor. Journal of the Society for Gynecological Investigations $20029233-237$.

19 Goland RS, Wardlaw SL, Stark RI, Brown LS Jr \& Frantz AG. High levels of corticotropin-releasing hormone immunoactivity in maternal and fetal plasma during pregnancy. Journal of Clinical Endocrinology and Metabolism 198663 1199-1203.

20 Nodwell A, Carmichael L, Fraser M, Challis J \& Richardson B. Placental release of corticotrophin-releasing hormone across the umbilical circulation of the human newborn. Placenta 199920 197-202.

21 Frim DM, Emanuel RL, Robinson BG, Smas CM, Adler GK \& Majzoub JA. Characterization and gestational regulation of corticotropin-releasing hormone messenger RNA in human placenta. Journal of Clinical Investigation $1988 \mathbf{8 2} 287-292$.

22 Florio P, Rivest S, Reis FM, Simoncini T, Martinelli P, Genazzani AR \& Petraglia F. Lack of gestational-related changes of urocortin gene expression in human placenta. Prenatal and Neonatal Medicine $19994296-300$.

23 Florio P, Severi FM, Ciarmela P, Fiore G, Calonaci G, Merola A, De Felice C, Palumbo M \& Petraglia F. Placental stress factors and maternal-fetal adaptive response: the corticotropin-releasing factor family. Endocrine 200219 91-102.

24 Glynn BP, Wolton A, Rodriguez-Linares B, Phaneuf S \& Linton EA. Urocortin in pregnancy. American Journal of Obstetrics and Gynecology $1998 \mathbf{1 7 9} 533-539$.

Received 18 July 2005

Accepted 14 November 2005 